\title{
KRITIK SOSIAL PADA NASKAH DRAMA ANAK WAYANG KARYA M.J. WIDJAYA
}

\author{
Ridana Dwi Dita Afrilla \\ Pendidikan Bahasa dan Sastra Indonesia, Fakultas Ilmu Pendidikan, Universitas \\ Muhammadiyah Jakarta, Jl. KH. Akhmad Dahlan Ciputat Cirendeu, Tangerang Selatan \\ rdwiditaafrilla@gmail.com
}

\begin{abstract}
Abstrak
Naskah drama Anak Wayang karya M.J Widjaya mencoba menggambarkan seorang penguasa atau raja yang tidak peduli kepada rakyat. Penelitian ini bertujuan untuk menghubungkan penggambaran yang terdapat pada naskah drama dengan kondisi sosial atau politik yang ada di Indonesia. Penelitian ini menggunakan kajian sosiologis sastra. Kajian sosiologi sastra merupakan pendekatan dengan melihat kenyataan yang ada atau gambaran fenomena sosial secara nyata. Metode yang digunakan dalam penelitian adalah metode kualitatif. Teknik pengumpulan data penelitian ini adalah dengan membaca naskah Anak Wayang, lalu menghubungkan penggambaran yang terdapat di naskah drama dengan kondisi nyata yang ada di Indonesia. Melalui naskah drama Anak Wayang, M.J Widjaya mengkritik kondisi sosial dan politik yang terjadi di Indonesia yang digambarkan dengan dialog-dialog tokoh pada naskah drama Anak Wayang. Pada naskah drama Anak Wayang ini, peneliti menemukan gambaran kondisi sosial dan politik seperti yang ada di Indonesia seperti kemiskinan atau masalah perekonomian dan birokrasi atau masalah pemerintahan.
\end{abstract}

Kata Kunci: drama, sosiologi sastra, kualitatif.

Abstract

The manuscript of the drama Anak Wayang by M.J Widjaya tries to portray a ruler or king who does not care for the people. This study aims to connect the depictions contained in the drama script with the existing social or political conditions in Indonesia. This study uses a sociological study of literature. The sociology of literature study is an approach by looking at existing facts or depicting real social phenomena. The method used in the research is a qualitative method. The data collection technique for this research is by reading the Anak Wayang script, then connecting the depiction contained in the drama script with the real conditions in Indonesia. Through the drama script Anak Wayang, M.J Widjaya criticizes the social and political conditions tha occur in Indonesia, which are described by the dialogues of the characters in the drama script Anak Wayang. In this drama script Anak Wayang, the researcher finds a picture of social and political conditions in Indonesia, such as poverty or economic and bureaucratic problems or government problems.

Keyword: drama, sociology of literature, qualitative. 
Pendahuluan Sastra adalah suatu media yang memadukan antara imajinasi dan realita yang diciptakan oleh pengarangnya. Karya sastra merupakan ekspresi dari seorang pengarang dan gambaran kehidupan nyata manusia. Pengarang bebas menuangkan imajinasinya ke bentuk karya sastra, salah satunya drama. Menurut Harymawan (dalam Fahmi, 2017) mengatakan drama berasal dari bahasa Yunani yaitu draomai yang berarti bertindak, berlaku, berbuat, beraksi, dan sebagainya. Menurut Tjahyono (dalam Fahmi, 2017) menyebutkan bahwa drama dapat diartikan sebagai bentuk seni yang berusaha mengungkapkan hal kehidupan manusia melalui gerak atau aksi dan percakapan atau yang lebih dikenal dialog. Menurut Waluyo (dalam Anwar, dkk, 2018) naskah drama bisa disebut dengan sastra lakon. Naskah drama memiliki struktur fisik (kebahasaan) dan struktur batin (semantik, makna). Struktur fisik pada drama yaitu berupa tokoh atau penokohan, latar, alur, dan dialog. Struktur batin drama berupa tema serta amanat. Amanat dalam drama dapat diketahui setelah pembaca melakukan proses membaca serta memahami dialog yang terdapat pada naskah drama, setelah itu baru dapat menangkap makna tersirat yang ingin disampaikan oleh pengarang. Proses membaca pada suatu karya sastra bukanlah proses mencari informasi, melainkan untuk mencari sebuah makna.

Karya sastra memiliki dua fungsi, fungsi hiburan dan bermanfaat. Menurut Suhardi (dalam Wahyuni, 2019) menyatakan bahwa karya sastra dalam penciptaannya memiliki dua latar belakang utama yaitu pertama unsur hiburan dan kedua unsur kritik sosial pengarang terhadap realitas yang terjadi di sekelilingnya. Karya sastra sebagai fungsi yang bermanfaat dapat menjadi media untuk menuangkan ide pengarang, yang biasanya ide tersebut di dapat dari kejadian nyata yang dilihat langsung oleh pengarang. Dalam fungsi bermanfaat ini pengarang dapat memasukan kritik sosial didalam karyanya, sehingga karya sastra tersebut sebagai wadah untuk menyampaikan kegelisahan mengenai keadaan sosial yang ada di sekitarnya. Menurut Suhardi (dalam Wahyuni, 2019) menyatakan pengarang dapat melakukan tindakan untuk memperbaiki suatu keadaan yaitu melalui kritik sosial yang diciptakan melalui karyanya. Maksudnya melalui karya sastra, pengarang dapat menyampaikan kegelisahan mengenai permasalahan sosial yang ada di sekitarnya. Kegelisahan yang disampaikan dalam bentuk karya sastra, yang didalamnya terdapat kritik, kritik yang merupakan perasaan tidak puas terhadap sesuatu hal. Dalam naskah drama Anak Wayang peneliti melihat pengarang menyampaikan kritiknya terhadap pemerintah atau pegawai pemerintah. Menurut peneliti, pengarang dalam menyampaikan kritiknya melalui karya sastra berharap adanya perubahan yang lebih baik terutama mengenai sistem pemerintahan. Pada naskah drama Anak Wayang, M.J Widjaya menggunakan pemilihan bahasa yang mudah dipahami sehingga peneliti tidak kesulitan untuk menemukan kritik atau pesan tersirat yang hendak disampaikan oleh penulis. Peneliti tertarik mengkaji kritik sosial dan politik yang terdapat pada naskah drama Anak Wayang karena belum ada penelitian sebelumnya yang mengkaji kritik sosial naskah drama tersebut. 
Drama dalam mengungkapkan kehidupan manusia tidak lepas dari karya sastra yang menyajikan gambaran atau fenomena sosial secara nyata. Gambaran atau fenomena sosial ini dapat berupa hubungan manusia dengan manusia, manusia dengan masyarakat, ataupun peristiwa. Hal ini berkaitan dengan sosiologi sastra. Menurut Devi (2019: 137) fenomena sosial bersifat konkret, terjadi di sekiling kita sehari-hari, bisa diobservasi, difoto, dan didokumentasikan. Pada naskah drama Anak Wayang ini terlihat jelas fenomena sosial yang sesuai dengan kenyataan yang ada di Indonesia, yaitu banyak penguasa yang tidak memperhatikan kesejahteraan rakyat dan membiarkan rakyat kelaparan. Hal ini bisa dilihat secara langsung di sekeliling kita, dan bisa dilihat melalui pemberitaan yang sering kali ada media massa mengenai masyarakat yang tidak sejahtera. Karya sastra dalam hal ini dapat berfungsi sebagai kritik sosial mengenai peran pemerintah. Menurut Sumaryono (dalam Mulyaningsih, 2017) pengarang sebagai bagian dari masyarakat dapat merasakan gejolak atau permasalahan yang terjadi di masyarakat. Berdasarkan pernyataan tersebut, dengan kata lain pengarang dapat menggunakan karya sastra sebagi media untuk menyampaikan kegelisahan mengenai fenomena yang terjadi di sekitarnya. Secara tidak langsung pengarang telah melakukan sindiran, dalam naskah Anak Wayang sindiran ini ditujukan kepada penguasa yang tidak memikirkan rakyatnya.

Sindiran yang terdapat pada naskah Anak Wayang yaitu mengkritik permasalahan sosial yang terjadi pada masyarakat. Masalah sosial itu merupakan persoalan yang terjadi di tengah-tengah kehidupan masyarakat. Menurut Soekanto (dalam Anwar, dkk, 2018) ada beberapa masalah yang terjadi di tengah masyarakat, yaitu kemiskinan, kejahatan, disorganisasi keluarga, pendidikan, lingkungan hidup, birokrasi, serta agama dan kepercayaan. Masalah sosial yang terdapat pada naskah Anak Wayang yaitu mengenai kemiskinan dan birokrasi.

Penelitian ini memaparkan kritik sosial yang terdapat pada naskah drama Anak Wayang hasil karya M.J Widjaya pada tahun 2008 dan menghubungkan penggambaran yang terdapat pada naskah drama dengan kondisi sosial atau politik yang ada di Indonesia. Naskah drama Anak Wayang didapat dari laman yang ada di internet. Penelitian ini menggunakan metode penelitian kualitatif yaitu metode yang bersifat mendeskripsikan, menganalisis pesan yang ada pada naskah drama, dan menggunakan teori sebagai pemahaman dalam mengkaji naskah drama. Menurut Ibrahim (2015: 52) metode kualitatif memfokuskan data berupa deskripsi kata atau kalimat yang nantinya dijadikan sebagai bahan penelitian, menandai dialog yang akan diteliti, lalu melaporkan hasil penelitian. Sumber data utama yang menjadi bahan penelitian adalah teks naskah Anak Wayang, serta yang menjadi sumber data kedua adalah teori-teori yang digunakan untuk mendukung pemahaman dalam proses penelitian. Berdasarkan penelitian ini, peneliti memaparkan kritik sosial yang terdapat pada naskah drama dan dihubungkan dengan fenomena nyata yang terjadi di Indonesia. Peneliti berusaha dengan baik dan serius agar hasil penelitian sesuai dengan fakta, teori maupun data yang ada. 
Ada beberapa cara dalam melakukan kajian pada novel ini yaitu 1) mengumpulkan sumber data utama (naskah drama), 2) mencari teori untuk menambah pemahaman dalam mengkaji naskah drama, 3) melakukan analisis sementara. Jadi, dalam mengkaji naskah drama kegiatan yang dilakukan adalah membaca terlebih dahulu naskah drama Anak Wayang, menghubungkan teori pendekatan yang akan digunakan seperti pendekatan sosiologi sastra dengan naskah drama, lalu menandai fenomena sosial yang terdapat pada naskah drama.

Pembahasan

Hasil penelitian yang dilakukan pada naskah drama Anak Wayang karya M.J Widjaya, peneliti menemukan 2 hal yang mengandung kritik sosial. Kritik sosial yang terdapat pada naskah drama Anak Wayang yaitu membahas mengenai kemiskinan atau masalah perekonomian dan birokrasi atau masalah pemerintahan. Hal tersebut terlihat jelas pada dialog-dialog yang ada pada naskah drama.

\section{A. Kemiskinan}

Menurut KBBI V (2016) arti dari miskin adalah tidak bertahta; serba kekurangan (berpenghasilan sangat rendah). Menurut Suparlan (dalam Anwar, dkk, 2018) kemiskinan adalah suatu standar tingkat hidup yang rendah, segolongan orang yang serba kekurangan serta berpengaruh terhadap tingkat keadaan kesehatan, kehidupan moral, dan rasa harga diri mereka yang tergolong orang miskin.

"Sekitar empat tahun yang lalu, saat itu aku dan raja berteman, tapi ketika dia mencalonkan menjadi raja, dia menyuruh aku agar aku berpura-pura menjadi menjadi pemberontak dan dia ingin menjadi pahlawan dan raja mengangkat dia menjadi menteri dan saat itu menyuruh aku lagi untuk memberontak dengan alasan kalau raja pada saat itu tidak dapat mensejahterakan rakyat, tanpa diduga dia menjadi raja. Saat itu dia menjadi raja banyak rakyat yang dirugikan. Para petani dipaksa agar hasil panennya diberikan kepada kerajaan dan dari kerjaan diberikan ke kerajaan tetangga. Banyak menteri-menteri yang memperkaya diri. Rakyat banyak yang mati kelaparan, anak-anak kecil banyak yang mati karena busung lapar. Coba kamu lihat keluar?"

"Coba kalau aku tidak membantu saat itu, mungkin rakyat tidak akan menderita seperti ini. Ini janji yang dulu kau ucapkan, apakah kelaparan yang telah kau berikan kepada rakyat? Apakah penyakit-penyakit yang tiada obatnya yang kau beri untuk anak-anak di negeri ini. Kau dan para menterimu hanya mementingkan diri sendiri, coba kalian pikir, sudah berapa banyak rakyat yang mati sia-sia, ini ulah kalian, kalian dengan enak membawa paksa hasil panen, guru-guru hanya boleh mengajarkan anak-anak para menteri, tabib-tabib hanya boleh mengobati keluarga raja dan menteri, apa itu semua yang telah kau berikan kepada rakyat?"

Pada kutipan dialog di atas terdapat kalimat "Rakyat banyak yang mati kelaparan, anak-anak kecil banyak yang mati karena busung lapar.” Kalimat 
tersebut mendeskripsikan gambaran kemiskinan yaitu rakyat (orang) yang serba kekurangan sehingga tidak dapat mencukupi hidupnya sehingga rakyat tersebut banyak yang kesehatannya terganggu sehingga mengalami busung lapar dan sampai menyebabkan kematian. Sesuai dengan arti kemiskinan yaitu suatu tingkat hidup orang yang rendah dan serba kekurangan berpengaruh terhadap tingkat kesehatan seseorang. Tingkat hidup rendah dan kekurangan yang menyebabkan para rakyat tidak dapat memenuhi keperluan pangan, sehingga berdampak pada kesehatan.

Masalah kemiskinan itu merupakan dampak dari perekonomian yang stabil. Dilihat dari realita kehidupan yang ada seperti negara Indonesia, peneliti menghubungkan dialog yang terdapat di naskah dengan berbagai pemberitaan yang ada di media massa seperti media elektronik dan media cetak yang terdapat pemberitaan rakyat yang sulit untuk memenuhi kebutuhan hidupnya terutama masyarakat yang hidup di pedalaman atau desa-desa yang ada di pelosok.

\section{B. Politik atau Birokrasi dan Kepemimpinan}

Menurut KBBI V (2016) arti dari politik adalah (pengetahuan) mengenai ketatanegaraan atau kenegaraan (seperti tentang sistem pemerintahan, dasar pemerintahan); segala urusan dan tindakan (kebijakan, siasat, dan sebagainya) mengenai pemerintahan negara atau terhadap negara lain. Menurut Deliar Noer yang dikutip Puluhuluwa dan Nambo (2005) menyebutkan bahwa politik adalah segala aktivitas atau sikap yang berhubungan dengan kekuasaan, memiliki maksud untuk mempengaruhi, dengan cara mengubah atau mempertahankan, suatu macam bentuk susunan masyarakat. Menurut KBBI V (2016) arti birokrasi adalah sistem pemerintahan yang dijalankan oleh pegawai pemerintahan yang berpegang pada hirearki dan jenjang jabatan. Menurut Ismail (dalam Ramadhanti, 2018: 100), birokrasi pemerintah merupakan suatu organisasi terdepan yang berhubungan dengan memberikan layanan kepada masyarakat. Menurut Martini (2012: 11) terdapat dua makna birokrasi yaitu makna positif dan makna negatif. Makna positif diartikan sebagai birokrasi bekerjan secara efisien dan efektif, sedangkan makna negatif diartikan sebagai alat penindas bagi suatu kaum yang lemah (miskin) serta hanya mengutamakan kepentingan orang kaya dan berkuasa.

"Sekitar empat tahun yang lalu, saat itu aku dan raja berteman, tapi ketika dia mencalonkan menjadi raja, dia menyuruh aku agar aku berpura-pura menjadi menjadi pemberontak dan dia ingin menjadi pahlawan dan raja mengangkat dia menjadi menteri dan saat itu menyuruh aku lagi untuk memberontak dengan alasan kalau raja pada saat itu tidak dapat mensejahterakan rakyat, tanpa diduga dia menjadi raja. Saat itu dia menjadi raja banyak rakyat yang dirugikan. Para petani dipaksa agar hasil panennya diberikan kepada kerajaan dan dari kerjaan diberikan ke kerajaan tetangga.

Banyak menteri-menteri yang memperkaya diri. Rakyat banyak yang mati kelaparan, anak-anak kecil banyak yang mati karena busung lapar. Coba kamu lihat keluar?” 
"Coba kalau aku tidak membantu saat itu, mungkin rakyat tidak akan menderita seperti ini. Ini janji yang dulu kau ucapkan, apakah kelaparan yang telah kau berikan kepada rakyat? Apakah penyakit-penyakit yang tiada obatnya yang kau beri untuk anak-anak di negeri ini. Kau dan para menterimu hanya mementingkan diri sendiri, coba kalian pikir, sudah berapa banyak rakyat yang mati sia-sia, ini ulah kalian, kalian dengan enak membawa paksa hasil panen, guru-guru hanya boleh mengajarkan anakanak para menteri, tabib-tabib hanya boleh mengobati keluarga raja dan menteri, apa itu semua yang telah kau berikan kepada rakyat?"

Pada kutipan dialog di atas terdapat kalimat "Saat itu dia menjadi raja banyak rakyat yang dirugikan." dan "Banyak menteri-menteri yang memperkaya diri." Berdasarkan dialog tersebut pengarang yaitu M.J Widjaya memberikan gambaran bahwa sistem pemerintahan yang dijalankan oleh pegawai pemerintah tidak menjalankan tugas sebagai mestinya, seperti yang telah diketahui bersama bahwa tugas dari pegawai pemerintah salah satunya adalah membuat seluruh rakyat sejahtera. Selain itu seluruh pegawai pemerintah seharusnya lebih mengutamakan kepentingan kelompok (rakyat) dibandingkan dengan kepentingan individu. Hal itu namun tidak sesuai dengan tugas dan juga janji yang diucapkan oleh pegawai pemerintah. Seperti yang digambarkan dalam dialog "Ini janji yang dulu kau ucapkan, apakah kelaparan yang telah kau berikan kepada rakyat? Apakah penyakit-penyakit yang tiada obatnya yang kau beri untuk anak-anak di negeri ini. Kau dan para menterimu hanya mementingkan diri sendiri, coba kalian pikir, sudah berapa banyak rakyat yang mati sia-sia, ini ulah kalian, kalian dengan enak membawa paksa hasil panen, guru-guru hanya boleh mengajarkan anak-anak para menteri, tabib-tabib hanya boleh mengobati keluarga raja dan menteri, apa itu semua yang telah kau berikan kepada rakyat?". Pada dialog tersebut terlihat jelas penguasa atau pegawai pemerintah justru membuat rakyat sengsara. Pada dialog tersebut juga terlihat diskriminasi terhadap sesama warga yaitu hanya anak-anak menteri yang boleh belajar dan juga mendapatkan jaminan kesehatan, padahal semua warga seharusnya mendapatkan hak yang sama. Peneliti mencoba menghubungkan gambaran yang ditulis oleh naskah M.J Widjaya dengan kejadian nyata, hal tersebut sesuai dengan Indonesia yang seperti diketahui dari media massa banyak pemberitaan mengenai rakyat Indonesia dengan keadaan perekonomian yang rendah sulit untuk mengenyam pendidikan dan sulit mendapatkan jaminan kesehatan. Hal tersebut bisa terjadi karena pada realitanya kegiatan pendidikan dan juga jaminan kesehatan tetap saja memerlukan biaya yang tidak bisa dipenuhi oleh semua rakyat, terutama rakyat yang memilki perekonomian rendah. "Aku akan memperjuangkan hak-hak anak bangsa ini, kita semua sama, bukan para saja yang boleh buang air." Pada dialog tersebut pengarang naskah drama Anak Wayang berusaha menyampaikan pendapatnya bahwa semua warga negara memiliki hak yang sama, tidak boleh ada diskriminasi antara penguasa (pegawai pemerintah) dan rakyat biasa. 
Kesimpulan Bersumber pada penelitian yang telah dilakukan tentang kajian kritik sosial naskah drama Anak Wayang karya M.J Widjaya, dapat disimpulkan terdapat kritik sosial yang membahas mengenai kemiskinan dan birokrasi. Penelitian ini bertujuan untuk menghubungkan penggambaran yang terdapat pada naskah drama dengan kondisi sosial atau politik yang ada di Indonesia. Gambaran kemiskinan seperti rakyat yang serba kekurangan sehingga tidak dapat mencukupi hidupnya, banyak rakyat yang kesehatannya terganggu sehingga mengalami busung lapar dan sampai menyebabkan kematian. Gambaran birokrasi seperti gambaran sistem pemerintahan yang dijalankan oleh pegawai pemerintah tidak dilakukan dengan baik, pegawai pemerintah seharusnya memberikan pelayanan kepada masyarakat dan membuat masyarakat sejahtera. Namun pada realitanya pemerintah membuat rakyat sengsara.

\section{Daftar Pustaka}

Devi, Wika Soviana. 2019. Teori Sastra. Karanganyar: CV Al Chalief.

Ibrahim. 2015. Metodologi Penelitian Kualitatif. Jakarta: Republika.

Mulyaningsih, Catur Tri. 2017. Kritik Sosial Dalam Naskah Drama Tik, Karangan Budi Yasin Musbach: Suatu Pendekatan Heurmeneutik. AKSIS. Volume 1. Nomor 2.

(http://journal.unj.ac.id/unj/index.p hp/aksis/article/view/5305 diakses pada 20 Juni 2020)

Fahmi, Ridzky Firmansyah. 2017. Pembelajaran Naskah Drama Melalui Bedah Naskah. Jurnal Forum Didaktik. Volume 1. Nomor 1.

(https://scholar.google.co.id/schola $\mathrm{r}$ ?hl=id\&as $\mathrm{sdt}=0 \% 2 \mathrm{C} 5 \& \mathrm{q}=$ Pembe lajaran + naskah + drama + melalui + be $\mathrm{dah}+$ naskah\&btn $\mathrm{G}=\# \mathrm{~d}=\mathrm{gs}$ qabs\&u $=\% 23 \mathrm{p} \% 3 \mathrm{DGUPM}$ diakses pada 20 Juni 2020)

Anwar, Febrina dan Syam, Akhmad. 2018. Kritik Sosial Dalam Naskah Drama Al Langkah Lucunya Negeri Ini Karya Deddy Mizwar. Volume 3. Nomor 6. (https://jurnal.untad.ac.id/jurnal/ind ex.php/BDS/article/view/10057 diakses 22 Juni 2020)

KBBI V Daring. 2016. Badan Pengembangan dan Pembinaan Bahasa, Kementerian Pendidikan dan Kebudayaan Republik Indonesia.

Wahyuni, Neneng. 2019. Kritik Sosial Dalam Karya Sastra Bentuk Nyata Protes Sastrawan. Volume 2. Nomor 2.

(https://journal.ipm2kpe.or.id/index. php/KIBASP/article/view/619 diakses pada 2 Juli 2020)

Martini, Rina. 2012. Buku Ajar "Birokrasi dan Politik". Semarang: UPT UNDIP Press Semarang.

Ramadhanti, Rika. 2018. Politik dan Birokrasi Pemerintahan. Volume 2. Nomor 1.

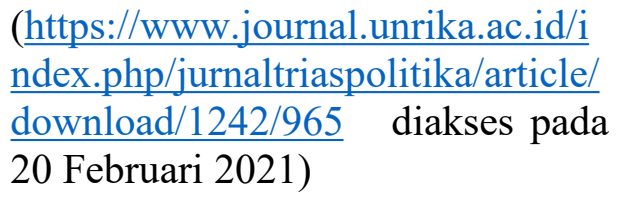

Nambo, Abdulkadir. B dan Puluhuluwa, Muhamad Rusdiyanto. 2005. Memahami Tentang Beberapa Konsep Politik (Suatu 
Telaah dari Sistem Politik). Volume 21. Nomor 2.

(https://www.google.com/url? sa=t \&rct $=\mathrm{j} \& \mathrm{q}=\&$ esrc $=\mathrm{s} \&$ source $=$ web \& $\underline{\mathrm{cd}=\& \mathrm{cad}=\text { rja\&uact }=8 \& v e d=2 \mathrm{ahU}}$ KEwjOyrj3iIzvAhWZf30KHUbEB wAQFjAAegQIARAD\&url=https $\% 3 \mathrm{~A} \% 2 \mathrm{~F} \% 2 \mathrm{Fejournal} . u n i s b a . a c . i d$ \%2Findex.php $\% 2$ Fmimbar $\% 2$ Farti cle $\% 2$ Fview $\% 2 \mathrm{~F} 177 \&$ usg $=\mathrm{AOvVa}$ w3 tKvdSRibcwZzUIaDWk53

diakses pada 21 Februari 2021) 